\title{
Weakened baroclinic activity causes an abrupt rise in fog in the Indo-Gangetic Plain
}

\author{
Udaya Bhaskar Gunturu ${ }^{1,2}$, Vinay Kumar $^{3}$ \\ ${ }^{1}$ King Abdullah University of Science and Technology, Thuwal, Saudi Arabia
${ }^{r}$ The MIT Joint Program on the Science and Policy of the Global Change, Massachusetts Institute of \\ Technology, Cambridge, MA 02 139, USA
${ }^{3}$ Department of Environmental Engineering, Texas Agricultural and Mechanical University, Kingsville, \\ TX 78363 , USA
}

\section{Key Points:}

- The boundary layer stability in the Indo-Gangetic Plain is maintained by deep subsidence, and the radiative cooling in the winter.

- A sudden decrease in the frequency and intensity of western disturbances enhanced cooling, and hence altered boundary layer physics.

- Altered dynamics, thermodynamics, and increased irrigation enhanced formation of fog since 1996-97.

Corresponding author: Udaya Bhaskar Gunturu, udayab@gmail.com

This article has been accepted for publication and ${ }^{-1}$ undergone full peer review but has not been through the copyediting, typesetting, pagination and proofreading process, which may lead to differences between this version and the Version of Record. Please cite this article as doi: 10.1029/2021GL096114.

This article is protected by copyright. All rights reserved. 


\begin{abstract}
Dense and widespread winter fog in the Indo-Gangetic Plain (IGP) causes a significant reduction in visibility and worsened air pollution. Despite extensive observational campaigns, the key processes in the formation and persistence of fog are not yet clear. The global increase in surface temperatures led to a decline in the incidence of fog, whereas the IGP experienced a sudden increase in fog incidence. It is shown here that abruptly reduced activity of the western disturbances (WD) around 1996-97 resulted in a sudden decline of the cloud cover in the region, with a concomitantly enhanced radiative cooling of the surface and the atmosphere. These abrupt changes, aided by the impacts of human activities, altered the dynamics and thermodynamics of the boundary layer to favor fog formation. Also, the critical role of the extensive deep subsidence in the modulation of stable stratification and turbulence, which are essential for fog formation, is elucidated.
\end{abstract}

\title{
Plain Language Summary
}

Atmospheric subsidence stabilizes the atmospheric boundary layer in the IndoGangetic Plain. Radiative cooling of the ground surface and the atmosphere further enhances the stable stratification and suppresses the turbulence. Western disturbances, which are baroclinic storms occurring in the IGP, cause formation of clouds in the middle and upper troposphere. A sudden decrease in their frequency and intensity since 1996-97 resulted in reduced cloud cover in the middle and upper troposphere in the region, and hence enhanced radiative cooling of the surface and the atmosphere. The enhanced radiative cooling created dynamical and thermodynamic conditions favorable for fog formation. Increased irrigation of crops during winter in the region further favored saturation of the air closer to the ground. As a result, the incidence of fog increased since 1996-97.

\section{Introduction}

The Indo-Gangetic Plain (IGP) experiences widespread and dense radiation fog Singh \& Kant (2006); Singh et al. (2007) for several days in winter (December and January). Fog causes extensive economic and agricultural losses and exacerbates accidents and pollution hazards Gupta \& Elumalai (2018).

Fog and haze both diminish visibility, but thermodynamically they are different. Haze results from a high concentration of aerosols in the atmosphere, whereas fog is high relative humidity, condensation and suspension of water droplets in the air Willett (1928). This study focuses on the physical processes pertaining to formation of saturation, and hence that of fog.

In winter, IGP has cooler surface temperatures, nearly a cloud-free atmosphere, light wind, and no transport of moisture from oceanic regions as the climatological wind flow is northeasterly during December-January, when the fog occurs Rajeevan et al. (2012); Yadav et al. (2012).

Despite extensive observational studies Ghude et al. (2017), many fundamental issues, including the atmospheric forcings conditioning the boundary layer (BL) for fog formation, are unclear: the spatial extent, the dynamical and thermodynamic processes, the source of moisture, and the generation and maintenance of turbulence.

Fog does not form due to radiative cooling of the ground alone Taylor (1917); essentially, it does when turbulent eddies at different temperatures, but close to saturation, mix adiabatically in a stable boundary layer (SBL) Taylor (1917) resulting in condensation. If the ground cools but the adjacent air does not, fog does not form Taylor (1917); Brown \& Roach (1976); Rodhe (1962). Thus, turbulent mixing of heat and water vapor, between the radiatively cooling surface and the air adjacent to it, are critical processes for fog formation Rodhe (1962). The delicate balance of dynamics and thermodynamics of radiative fog in the IGP, and the critical role of turbulent mixing is described in Supplementary Information (SI). 
Increasing stable stratification makes the dynamics of turbulence very subtle and has a significant impact on the formation and dissipation of fog Wyngaard (2010). In an SBL, the shear-generated turbulence dominates that generated by buoyancy Mahrt (1985). Buoyancy significantly destroys turbulent kinetic energy (TKE) at the energy-containing (large) scales Stull (2012). The rate of transfer of TKE from these scales to the molecular scales, through the Kolmogorov energy cascade, maintains the rate of viscous dissipation Stull (2012). Strong stable stratification causes buoyant destruction of TKE in the energy-containing scales; the energy cascade of TKE to the molecular scales is shut down Wyngaard (2010), and fog is dissipated. Thus, the stable stratification, by modulating the size of the largest eddy (hence the highest TKE), controls the cascade, and the exchange of heat and moisture fluxes with the surface (elaborated in SI).

Subsidence in the IG Plain is extensive and deep. It is generally commented that this subsidence creates high pressure at the surface and hence causes fog Hingmire et al. (2019); Ghude et al. (2017). But, there have not been studies that look at the dynamical and thermodynamic impacts of such a widespread subsidence. This study argues, using dynamical processes, that the extensive subsidence controls the spatial extent.

The winter high pressure in the IG Plain is eroded by western disturbances. Western disturbances are intermittent synoptic scale systems originating from barotropic instability on the subtropical jet north of the Indian Subcontinent Dimri \& Chevuturi (2016); Hunt et al. (2019). Since they bring cold and dry air from the north to the IG Plain in the mid- and upper-troposphere, the usual anti-cyclonic circulation at that level (500 mbar) is changed to cyclonic circulation Hingmire et al. (2019). When there is sufficient water vapor in the boundary layer, the cyclonic circulation caused by the western disturbances causes deep explosive convection resulting in rain in the region. This deep convection associated with the western disturbances disturbs the stability of the boundary layer. Thus, they impact the formation of fog in the region Hingmire et al. (2019).

We show in this study that most of the dynamical and thermodynamic variables associated with radiative cooling and fog formation underwent an abrupt change during 1996-97. Abrupt changes are fast changes in the distribution of a variable with reference to the sampling period Basseville \& Nikiforov (1993). Before and after the abrupt change, the statistical properties are assumed to be constant and different Basseville \& Nikiforov (1993).

In the subsequent sections, we argue, using surface observations and reanalysis data, that (a) the extensive subsidence in the IG Plain creates stable stratification, but this stability of the boundary layer is not sufficient for development of saturation, (b) the radiative cooling of the surface and the atmosphere enhances the stability of the boundary layer and facilitates development of saturation, and (c) the western disturbances (WD) have significant impact on the radiative cooling. Thus, we show that the abrupt change in the frequency and strength of the baroclinic activity in the region (Western disturbances are baroclinic storms), during 1996-97, has resulted in an abrupt change in the surface temperature, and the boundary layer dynamics and thermodynamics, making the air close to the ground favorable to saturation.

\section{Data and Methods}

\subsection{Data}

The data for this study consist of:

- Monthly values (December and January) of vertical pressure velocity, water vapor mixing ratio, high-, middle-, and low-cloud fractions, outgoing longwave radiation at the top of the atmosphere, friction velocity, and exchange coefficients (of momentum, heat and water vapor) were taken from the MERRA-2 Reanalysis dataset Gelaro et al. (2017).

- Meteorological variables at the Safdarjung airport in Delhi - surface temperature, dewpoint temperature, visibility, and surface wind speed, surface pressure - were 
Figure 1. Subsidence in the IGP in the fog season (December and January). (a) Vertical pressure velocity $\left(\mathrm{mbarh}^{-1}\right)$ at $900 \mathrm{mbar}$ level (b) Vertical profile of vertical pressure velocity $\left(\omega, \mathrm{mbarh}^{-1}\right)$ and water vapor $\left(q, \mathrm{gkg}^{-1}\right)$ averaged in the IGP (green contours (a)). The high subsidence in the IGP coincides with the region of fog occurrence.

taken from the National Climate Data Center (NCDC, Oliver (2005)). The water vapor mixing ratio has been derived.

- Time series of crop area EPW Research Foundation (2019), and power consumption for irrigation using tube wells EPW Research Foundation (2019) during the Rabi season have been taken from the Economic and Political Weekly Research Foundation (EPWRF), which is an aggregation of data from the central and the provincial governments in India.

\subsection{Methods}

The MERRA data variables from grid points in each of the states in the IGP - Punjab, Haryana, Delhi, Uttar Pradesh, Bihar (including Jharkhand) - have been aggregated to generate the spatially averaged variables in each state, and they have been combined to form the time series for the IGP. The annual fog variables in the season (December and January) are smoothed using locally estimated scatter-plot smoothing with an 18-year span. The variables have also been normalized for easy comparison.

\subsubsection{Changepoint determination}

A changepoint Basseville \& Nikiforov (1993) is the time instance when the distribution of a time series changes. Determination of a changepoint consists of (a) detection if a change has occurred, and (b) finding the time instant $(\tau)$ of the abrupt change. Assuming the means of the time series before and after $\tau$ are $\mu_{1}$ and $\mu_{2}$,

$$
f(t)= \begin{cases}\mu_{1} & \text { if } t \leq \tau \\ \mu_{2} & \text { if } t>\tau\end{cases}
$$

- The time series is segmented into two sections $S_{1}$ and $S_{2}$ at time $\tau$.

- The means before and after $\tau, \mu_{1}$ and $\mu_{2}$ are computed.

- The deviations of the points from the corresponding mean $\left(\mu_{1}\right.$ or $\left.\mu_{2}\right)$ are added to get the total residual error.

$$
\Delta(\tau)=\sum_{j=1}^{\tau}\left(y_{j}-\bar{y}_{1: \tau}\right)^{2}+\sum_{j=\tau+1}^{n}\left(y_{j}-\bar{y}_{\tau+1: n}\right)^{2}
$$

- $\hat{\tau}$ with the minimum $\Delta(\tau)$ is chosen as the changepoint.

Mann-Whitney test was used to test the statistical significance of the change in distribution at the changepoint.

\section{Results}

\subsection{The role of subsidence}

A dynamical feature not considered in earlier studies is the substantial and widespread atmospheric subsidence in the region (Figure 1a); it descends to the ground with a maximum at $800 \mathrm{mbar}\left(\approx 1.4 \mathrm{mbarh}^{-1}\right.$; Figure $1 \mathrm{~b}$, Figure S1). Subsidence has a 
Figure 2. Abrupt changes in atmospheric and boundary layer characteristics relevant to fog in the IGP. (a) Normalized vertical pressure velocity $\left(\omega_{i}, \mathrm{mbarh}^{-1}\right)$, surface wind speed $\left(v_{s}, \mathrm{~ms}^{-1}\right)$, Richardson number $\left(R_{i}\right)$ and surface temperature $\left(T_{s},{ }^{\circ} \mathrm{C}\right),(\mathrm{b})$ High cloud fraction (\%), (c) Outgoing longwave radiation (OLR) flux at the top of the atmosphere $\left(\mathrm{Wm}^{-2}\right),(\mathrm{d})$ Richardson number (unitless), (e) Friction velocity $\left(\mathrm{ms}^{-1}\right)$, and (f) Exchange coefficient of heat $\left(\mathrm{kg} \mathrm{m}^{-2} \mathrm{~s}^{-1}\right)$. All the variables are from the MERRA-2 dataset. Timeseries of the variable (light grey), the smoothed variable (green), mean values before and after the abrupt change (red), and the year of the abrupt change (vertical dotted line) are shown in panels (b)-(f). The mean before (blue) and after (red) the changepoint, and the percentage change (maroon) are shown in corners.

profound role in the maintenance of stable stratification and turbulence in an SBL; it inhibits cloud formation and enhances the radiative cooling of the surface and the atmosphere Carlson \& Stull (1986). As the SBL grows in response to radiative cooling of the surface and turbulence, the horizontal divergence associated with subsidence advects the cold air at the top of the SBL and replaces with warm air. Such entrainment of heat increases buoyant destruction of TKE, resulting in a shallower SBL and weaker mixing Carlson \& Stull (1986). Furthermore, as a result of the enhanced temperature of the top of the SBL, the turbulent heat exchange between the top of the SBL and the ground surface is enhanced Carlson \& Stull (1986), hence favoring saturation by mixing. Such significant conditioning of the SBL by subsidence shows that the spatial extent of fog is well determined by that of subsidence (Figure 1a).

\subsection{Abrupt change in the incidence of fog}

As global temperatures increase, observations show a declining incidence of fog globally except in the IGP Klemm \& Lin (2016); Kutty et al. (2019). Surface observations at Safdarjung airport in Delhi also show decreased visibility due to fog Ghude et al. (2017); Jenamani (2007). This contrarily rising incidence of fog indicates that the dynamics of formation and persistence of fog in the IGP is different from that in the other regions of the world.

Several fog variables - dynamic and thermodynamic - changed abruptly around 199697 (Figure 2a) in the IGP and several provinces in the IGP (Figure S2): subsidence at the top of the BL $(28 \%)$, surface wind speed (-3.7\%), surface Richardson number $(52 \%)$, and surface temperature $(-2.6 \%)$. We argue that such a regime shift was a result of an abrupt reduction in cloud cover. The middle, and high cloud fractions decreased $(-26.9 \%$ and $20 \%$ respectively) between $1996-99$ (Figure S4b, and 2b), and the concomitant increase in the longwave radiation escaping to space at the top of the atmosphere $\left(\approx 5 \mathrm{Wm}^{-2}\right.$; Figure 2c) resulted in decreased surface temperature. Consequently, the stable stratification (as shown by the increased Richardson number, Figure 2d) increased and the turbulence intensity (measured by the friction velocity $(-8 \%)$, which accounts for the effects of the large-scale pressure field Businger (1982); Figure 2e) decreased. Reduced eddy exchange coefficients maintain sufficient cooling and water vapor locally for fog formation and maintenance (Figures 2f, S3a, and S3b).

The magnitude of low cloud cover $(\approx 2 \%)$, which may include fog and stratus clouds, is low compared to that of middle $(\approx 4 \%)$ and high $(\approx 16 \%)$ cloud cover, with similar differences in their fluctuations. Further, the middle and high cloud cover and water vapor at those levels are more impactful for greenhouse effect, and hence for radiative cooling. Incidentally, the low cloud cover also reflects the changes in rainfall associated with baroclinic activity. At the same time, the lowered subsidence (Figure S3d), although it is still high, resulted in decreased entrainment of heat (at the top of the SBL), which further reduced the buoyant destruction of TKE. Resultantly, the SBL starts becoming less shallow and the mixing was enhanced. The lowered temperature of the top of the boundary layer 
Figure 3. Surface observations at Safdarjung airport in Delhi. (a) Visibility (km) and relative humidity, (b) dewpoint temperature $\left({ }^{\circ} \mathrm{C}\right)$, (c) water vapor mixing ratio $\left(\mathrm{g} \mathrm{kg}^{-1}\right)$, (d) surface temperature $\left({ }^{\circ} \mathrm{C}\right)$ with the smoothed variable (red line)

Figure 4. Rainfall due to western disturbances and surface temperatures in the IGP. (a) Rainfall due to WD (light blue)and the trend line (green), (b) surface temperature (light blue) and the trend line (green), (c) joint distribution of WD rainfall and surface temperature showing two distinct regimes before 1997 (blue) and after (green), (d) kernel density plot of WD rainfall, and (e) kernel density plot of surface temperature. Distributions of quantities before and after 1997 are shown in blue and green respectively. The trend lines have been computed using LOWESS with a smoothing window fraction of $1 / 3$. The blue and red dotted lines show the mean quantities in (a) and (b) before $\left(\mu_{p}\right)$ and after $\left(\mu_{s}\right)$ 1997, which have also been shown on the plots.

resulted in decreased eddy heat flux between the top of the SBL and the ground surface (Figure 2f).

Thus, the most important thermodynamic and dynamic factors for the formation of the SBL and fog - turbulence, radiative cooling, subsidence, and advection (decreased surface wind speed) - were abruptly altered to favor enhanced stable stratification and fog formation, culminating in drastic reduction in visibility (Figure 3a).

A vital missing link is the source of water vapor. An increasing dewpoint temperature (Figure 3b) essentially indicates the role of increasing water vapor (Figure 3c, and S2f), and not that of the decreasing surface temperature. It was suggested that western disturbances (WD) transport moisture Dimri \& Chevuturi (2016), but they are dry and cold air masses in the middle and upper troposphere Hunt et al. (2018) which cannot transport moisture. We argue that the source of moisture is local. The atmosphere in the region is dry in the season with a surface water vapor mixing ratio of $\approx 3.5 \mathrm{~g} \mathrm{~kg}^{-1}$ (Figure 1a). The turbulence in the air near the surface evaporates surface water and hence maintains the water vapor mixing ratio, which is corroborated by the high correlation between evaporation by turbulence and the atmospheric specific humidity (Figure S5).

In response to a rising green revolution, the need to grow more food, and declining monsoon rainfall Turner \& Annamalai (2012), the IGP began to depend on groundwater. Fortuitously, during the 1990s many provincial governments in the IGP legislated to provide subsidized power for agriculture, resulting in increased extraction of groundwater Badiani \& Jessoe (2013); and, increased rate of evaporation enhanced water vapor in the BL (Figure 3c). The area under irrigation during the Rabi (Figure S6a) cropping season, and the power consumption for irrigation had increased till 1996-97 and stayed almost constant after (Figure S6b).

An obvious question arising is, why did the incidence of middle- and high-clouds decrease? WD, which are baroclinic instabilities Hunt et al. (2018), impact the boundary layer, and hence the fog, in three important ways. First, WD cause cumulonimbus clouds which transform into middle and high-clouds Hunt et al. (2018), which enhance the greenhouse effect and hence raise the surface temperatures. Second, the vertical transport of moisture from the boundary layer into the middle and upper troposphere enhances the greenhouse effect, raises the surface temperature, and inhibits fog formation. Third, the deep convection associated with WD disrupts the stability of the boundary layer.

Therefore, an abruptly decreased frequency of WD Kumar et al. (2015); Hunt et al. (2019) since 1996-97 had resulted in a lowered cloud cover, surface temperature, and mixing, and thus enhanced the stability of the boundary layer. Cloud cover reduces radiative cooling to an extent that it can no longer counter the diffusion of heat by turbulence to the ground Brown \& Roach (1976). A reduced winter rainfall (Figure 4a), which is essentially due to WD, since 1996-97 corroborates the reduced frequency of the WD. The 
impact of the reduced frequency of the WD on the surface temperature can be ascertained from Figure 4. Figures $4 \mathrm{a}$ and $4 \mathrm{~b}$ show the time series of the WD rainfall and surafce temperatures in the IG Plain. The mean rainfall before 1996-97 is slightly higher than that after, and the mean surface temperature before 1996-97 is higher than that after. The joint distribution of WD rainfall and the surface temperature (Figure 4c) shows two distinct regimes corresponding to pre-1997 and post-1997 times, although there is a slight overlap. Further, the distributions of WD rainfall and surface temperature show that a reduced WD rainfall (green curve in Figure 4d) corresponds to a reduced surface temperature (green curve in Figure 4e), both after 1996-97.

On the other hand, a temporary increase in WD activity during 2016-2018, as shown by the sudden rise in rainfall (Figure 4a), resulted in sharp momentary changes in several boundary layer parameters (Figures 3, S3, and S4); the consequent reduction in the incidence of fog enhanced visibility (Figure 3a).

\section{Discussion}

In this study we argue, using dynamic and thermodynamic arguments, that the deep subsidence in the whole IG Plain is one of the critical large-scale forcings that maintain the stable stratification in the region. Effectively, it reduces the largest scale of turbulence, but the heat due to adiabatic warming caused by subsidence is advected to the ground surface, hence inhibiting saturation; thus, the stable stratification and reduction of TKE caused by subsidence are not enough for fog formation.

We forward the hypothesis that further enhancement of stable stratification and lowering of TKE, caused by radiative cooling of the ground surface and the atmosphere, further reduces the largest scale of turbulence; hence, the advection of subsidence-caused heating to the ground surface is inhibited. Thus, subsidence and radiative cooling together maintain the conditions for saturation in the air adjacent to the ground surface.

Western disturbances, as an important synoptic phenomenon in winter, modulate the radiative cooling by changing the amount of high and middle cloud cover. When the activity of WD (frequency and intensity) increases, the cloud cover increases, with consequent reduction of radiative cooling, and vice versa.

Since the activity of WD abruptly decreased in 1996-97, the cloud cover decreased, thus enhancing radiative cooling. Abrupt changes in the characteristics of the stable boundary layer, and the concomitant impacts provide circumstantial evidence for the hypothesis that tries to explain the abrupt increase of fog after 1996-97. A schematic illustrating the physical processes discussed in this study and the changes in them is shown in Figure S8 (SI).

After 1996-97, the frequency and intensity of western disturbances decreased, which resulted in decreased middle and high cloud cover. As a consequence, the ground surface and the atmosphere lost more longwave radiation to the space; hence, the surface temperatures decreased resulting in enhanced stable stratification and suppressed turbulence.

Since the turbulence decreased, the vertical mixing of water vapor over long vertical scales had also been inhibited. Therefore, water vapor, aerosols, and pollutants are largely concentrated near the ground. All those changed conditions effectively favored flux of water vapor to the fog level from the ground surface, and heat from the fog level to the ground, thus bringing the fog level to saturation. Thus, the conditions were favorable to fog formation.

Western disturbances generate mid-tropospheric cyclonic circulation. Comprehensive analysis of the synoptic conditions associated with fog in the IG Plain (Hingmire et al. (2019)) showed the presence of a significant anti-cyclonic circulation, which shows absence or weakening of baroclinicity. Such an anticyclonic circulation in the upper troposphere is also indicated by anomalous easterly component of the horizontal winds. The analysis showed the absence of western disturbances, which are synoptic-scale baroclinic mid-tropospheric disturbances from the Mediterranean. Arctic Oscillation and Eurasian Teleconnections have been reported to modulate this mid-tropospheric circulation. 
Increased pollution has also been alleged to enhance the incidence of fog Ghude et al. (2017). Formation of fog is a two-step process: (a) formation of saturation, which is impacted by the meteorological processes; and (b) activation of aerosol particles in the saturated atmosphere to form droplets, which is influenced by the properties of aerosols. Increased relative humidity (Figure 3a), which is crucial for increased fog incidence, is a result of the dynamical and thermodynamic processes. The effect of increased aerosols is to absorb water vapor and mitigate relative humidity, thus contrary to the observations (increased relative humidity, Figure 3a). Generally, in regions with low water vapor, like the IGP, an increased hygroscopic aerosol concenration lowers the relative humidity (by absorption of water vapor) and inhibits fog formation Mazoyer et al. (2019). Thus, pollutants cannot explain the abrupt change in fog incidence. Further, the diffusion rate of water vapor into aerosols is slow and their activation into fog droplets is inhibited Pruppacher \& Klett (2010). Also, this hypothesis cannot explain the abrupt changes in several dynamical and physical conditions, like decreased cloud fraction and surface temperatures (Figure S2d), increased OLR at the top of the atmosphere (Figure 2c), and the downward LW radiation at the surface (Figure S4e). Also, planetary circulations (Arctic Oscillation and Eurasian teleconnections) are speculated Hingmire et al. (2019)to modulate the fog via reduced subsidence. But reduced subsidence cannot result in reduced cloud cover as shown here.

The incidence of fog will reduce in the IGP, as a result of one or more of the following changes. In a warming world, saturation of the boundary layer may occur with reduced magnitude and frequency, as observed in other parts of the world. The abrupt decrease in the cloud cover reverses, due to natural variability; in fact, satellite data show that the spatial extent of fog in the IGP decreased dramatically during 2002-2008 Saraf et al. (2011) when the cloud cover increased (Figure 2b) and WD activity increased (Figure 4). Lastly, better water management during the winter season or the receding underground water levels may lead to lower moisture in the boundary layer in the region. If the increasing temperatures reduce the incidence of fog, interestingly, the fog will be mitigated spontaneously before it would have been even understood or modeled accurately. Meanwhile, spikes in WD activity, by reducing the stability of the atmosphere, provide short-lived respite from the fog and air pollution.

An important caveat of this study is the choice of the rainfall, based on reports that show that the rainfall during these months robustly represents the WD activity, during the fog season (December \& January) as a proxy for WD activity (frequency and magnitude). WD rainfall is episodic, and all WDs do not result in rainfall. They do when water vapor is available in the lower atmosphere. Thus, rainfall underestimates the WD activity Hunt et al. (2019). The assumption of homogeneity of the fields in the IGP and consideration of spatial means is another limitation. The spatial mean values over different provinces of the IGP have also been shown in the SI. A further caveat is the assumption that segments of the time series before and after the changepoint are normally distributed.

Theoretical understanding and modeling of the inherent processes, the spatial extent, and the timing of formation and dissipation of fog have always been challenging Gultepe et al. (2007). The challenge is further aggravated in the IGP. First, the increased buoyant destruction of shear-generated TKE due to increased stable stratification and the shutting down of the Kolmogorov energy cascade constitute a delicate balance between very small quantities Wyngaard (2010) (Appendix A). Second, a very stable boundary layer (which is a necessary condition for fog) tends to be intermittently turbulent. As the stability increases further, the turbulence becomes further intermittent and weaker, thus making understanding and modeling the processes particularly challenging. Third, the diffusion of water vapor from and to the droplets is a strong function of the ambient water vapor concentration; when the ambient water vapor and the temperature are low, condensation is slow and the condensate is tiny $\left(0.01 \mathrm{~g} \mathrm{~kg}^{-1}\right.$ to $0.4 \mathrm{~g} \mathrm{~kg}^{-1}$ Ghude et al. (2017), compared to $7 \mathrm{~g} \mathrm{~kg}^{-1}$ in clouds). Such small quantities of condensate are usually less than the error of approximation of representation of Kóhler's theory in models. Therefore, it is challenging for models based on Kóhler's theory to accurately estimate the condensate, and concomitantly visibility. Effectively, the dynamic and thermodynamic balances in fog are between very small quantities; hence, formation, maintenance, and dissipation of fog tend to be stochastic (SI). Any attempt to simulate or forecast fog in the IGP needs to take these issues into consideration and represent these processes very robustly and accurately. 


\section{Acknowledgments}

We gratefully acknowledge the support of the MIT Joint Program on the Science and Policy of Global Change by the government, industry and foundation funding, the MIT Energy Initiative, and industrial sponsors. We thank the King Abdullah University of Science and Technology (KAUST) for supporting Udaya Bhaskar Gunturu. Vinay Kumar has been supported by the Texas A\&M University, Kingsville.

\subsection{Data availibility}

We thankfully acknowledge the providers of the data used in this study. The links to the sources of the data are listed here below.

- MERRA-2 data Gelaro et al. (2017):

https: //disc.gsfc.nasa.gov/datasets?keywords=\%22MERRA-2\%22\&page=1\&source= Models $\% 2 F$ Analyses $\% 20$ MERRA-2

The data used for this study consists of the following datasets:

- MERRA-2 int3_3d_asm_Np: 3d, 3-Hourly, Instantaneous, Pressure-Level, Assimilation, Assimilated Meteorological Fields Monthly Mean.

- MERRA-2 tavg1_2d_x_Nx: 2d, 1-Hourly, Time averaged, Single-Level, Assimilation, Surface Flux Diagnostics, Monthly Mean.

- Meteorological variables at the Safdarjung airport in Delhi: https://www.ncdc .noaa.gov/isd

- Agricultural data like crop area, and power consumption for irrigation using tube wells: http://epwrfits.in/

U.B.G. conceived and formulated the study and directed the research. U.B.G. and V.K. prepared the figures, and analyzed the results. Both the authors discussed the results and prepared the manuscript.

The authors declare no competing interests. 


\section{References}

Badiani, R., \& Jessoe, K. (2013). The impact of electricity subsidies on groundwater extraction and agricultural production (Tech. Rep.). Department of Agriculture and Resource Economics Working Paper, University of California Davis.

Basseville, M., \& Nikiforov, I. V. (1993). Detection of abrupt changes: theory and application (Vol. 104). Prentice Hall Englewood Cliffs.

Brown, R., \& Roach, W. T. (1976). The physics of radiation fog: II - a numerical study. Quarterly Journal of the Royal Meteorological Society, 102(432), 335-354. Retrieved from https://rmets.onlinelibrary.wiley.com/doi/abs/10.1002/ qj.49710243205 doi: 10.1002/qj.49710243205

Businger, J. A. (1982). Equations and Concepts. In F. T. M. Nieuwstadt \& H. van Dop (Eds.), Atmospheric Turbulence and Air Pollution Modelling: A Course held in The Hague, 21-25 September, 1981 (pp. 1-36). Dordrecht: Springer Netherlands. doi: 10.1007/978-94-010-9112-1_1

Carlson, M. A., \& Stull, R. B. (1986, August). Subsidence in the Nocturnal Boundary Layer.

Journal of Climate and Applied Meteorology, 25(8), 1088-1099. Retrieved from https://journals.ametsoc.org/doi/abs/ 10.1175/1520-0450 (1986) 025\%3C1088: SITNBL\%3E2.0.CO\%3B2 doi: $10.1175 /$ 1520-0450(1986)025\{\textless\}1088:SITNBL\{ \textgreater\}2.0.CO;2

Dimri, A. P., \& Chevuturi, A. (2016). Western Disturbances : Impacts and Climate Change. In A. P. Dimri \& A. Chevuturi (Eds.), Western Disturbances - An Indian Meteorological Perspective (pp. 113-127). Cham: Springer International Publishing. doi: 10.1007/978-3-319-26737-1_5

EPW Research Foundation. (2019). Power sector: 1973-74 to 2015-2016.

Gelaro, R., McCarty, W., Suárez, M. J., Todling, R., Molod, A., Takacs, L., ... Zhao, B. (2017, May). The Modern-Era Retrospective Analysis for Research and Applications, Version 2 (MERRA-2). Journal of Climate, 30 (14), 54195454. Retrieved from https://journals.ametsoc.org/doi/full/10.1175/ JCLI-D-16-0758. 1 doi: 10.1175/JCLI-D-16-0758.1

Ghude, S. D., Bhat, G. S., Prabhakaran, T., Jenamani, R. K., Chate, D. M., Safai, P. D., ... Rajeevan, M. (2017). Winter fog experiment over the IndoGangetic plains of India. Current Science, 112, 767-784. Retrieved from http://dx.doi.org/10.18520/cs/v112/i04/767-784 doi: http://dx.doi.org/ $10.18520 / \mathrm{cs} / \mathrm{v} 112 / \mathrm{i} 04 / 767-784$

Gultepe, I., Tardif, R., Michaelides, S. C., Cermak, J., Bott, A., Bendix, J., ... Cober, S. G. (2007, June). Fog Research: A Review of Past Achievements and Future Perspectives. Pure and Applied Geophysics, 164(6), 11211159. Retrieved from https://doi.org/10.1007/s00024-007-0211-x doi: 10.1007/s00024-007-0211-x

Gupta, S. K., \& Elumalai, S. P. (2018). Adverse impacts of fog events during winter on fine particulate matter, CO and VOCs: A case study of a highway near Dhanbad, India. Weather, 73(12), 396-402. doi: https://doi.org/10.1002/wea.3000

Hingmire, D., Vellore, R. K., Krishnan, R., Ashtikar, N. V., Singh, B. B., Sabade, S., \& Madhura, R. K. (2019, May). Widespread fog over the Indo-Gangetic Plains and possible links to boreal winter teleconnections. Climate Dynamics, 52(9), 5477-5506. Retrieved from https://doi.org/10.1007/s00382-018-4458-y doi: $10.1007 / \mathrm{s} 00382-018-4458-\mathrm{y}$

Hunt, K. M. R., Turner, A. G., \& Shaffrey, L. C. (2018). The evolution, seasonality and impacts of western disturbances. Quarterly Journal of the Royal Meteorological Society, 144(710), 278-290. Retrieved from https://rmets.onlinelibrary .wiley.com/doi/abs/10.1002/qj.3200 doi: 10.1002/qj.3200

Hunt, K. M. R., Turner, A. G., \& Shaffrey, L. C. (2019, May). Falling Trend of Western Disturbances in Future Climate Simulations. Journal of Climate, 32(16), 5037-5051. Retrieved from https://journals.ametsoc.org/doi/full/10.1175/ 
JCLI-D-18-0601.1 doi: 10.1175/JCLI-D-18-0601.1

Jenamani, R. K. (2007). Alarming rise in fog and pollution causing a fall in maximum temperature over Delhi. Current Science, 93(3).

Klemm, O., \& Lin, N.-H. (2016). What Causes Observed Fog Trends: Air Quality or Climate Change? Aerosol and Air Quality Research, 16(5), 1131-1142. Retrieved from https://doi.org/10.4209/aaqr.2015.05.0353 doi: 10.4209/aaqr.2015.05 .0353

Kumar, N., Yadav, B. P., Gahlot, S., \& Singh, M. ～(2015, January). Winter frequency of western disturbances and precipitation indices over Himachal Pradesh, India: 1977-2007. Atmósfera, 28(1), 63-70. Retrieved from http:// www.sciencedirect.com/science/article/pii/S0187623615721600 doi: 10.1016/S0187-6236(15)72160-0

Kutty, S. G., Dimri, A. P., \& Gultepe, I. (2019). Climatic trends in fog occurrence over the Indo-Gangetic plains. International Journal of Climatology. doi: 10.1002/ joc. 6317

Mahrt, L. (1985, November). Vertical Structure and Turbulence in the Very Stable Boundary Layer. Journal of the Atmospheric Sciences, 42(22), 23332349. Retrieved from https://journals.ametsoc.org/doi/abs/10.1175/ 1520-0469 (1985) 042\%3C2333:VSATIT\%3E2.0.CO\%3B2 doi: $10.1175 / 1520$ -0469(1985)042\{\textless\}2333:VSATIT\{ \textgreater $\} 2.0 . \mathrm{CO} ; 2$

Mazoyer, M., Burnet, F., Roberts, G. C., Haeffelin, M., Dupont, J.-C., \& Elias, T. (2019, April). Experimental study of the aerosol impact on fog microphysics. Atmospheric Chemistry and Physics, 19(7), 4323-4344. Retrieved from https : //www . atmos-chem-phys .net/19/4323/2019/acp-19-4323-2019.html doi: https://doi.org/10.5194/acp-19-4323-2019

Oliver, J. E. (2005). National Climate Data Center/Data Sources. In J. E. Oliver (Ed.), Encyclopedia of World Climatology (pp. 524-525). $\quad$ Dordrecht: Springer Netherlands. doi: 10.1007/1-4020-3266-8_147

Pruppacher, H., \& Klett, J. D. (2010). Microphysics of Clouds and Precipitation (Second ed., Vol. 18). Springer Netherlands. doi: 10.1007/978-0-306-48100-0

Rajeevan, M., Unnikrishnan, C. K., Bhate, J., Kumar, K. N., \& Sreekala, P. P. (2012). Northeast monsoon over India: variability and prediction. Meteorological Applications, 19(2), 226-236. Retrieved from https://rmets.onlinelibrary .wiley.com/doi/abs/10.1002/met.1322 doi: 10.1002/met.1322

Rodhe, B. (1962). The effect of turbulence on fog formation. Tellus, 14(1), 49-86. Retrieved from https://onlinelibrary.wiley.com/doi/abs/10.1111/j .2153-3490.1962.tb00119.x doi: 10.1111/j.2153-3490.1962.tb00119.x

Saraf, A. K., Bora, A. K., Das, J., Rawat, V., Sharma, K., \& Jain, S. K. $\quad$ (2011, July). Winter fog over the Indo-Gangetic Plains: mapping and modelling using remote sensing and GIS. Natural Hazards, 58(1), 199-220. Retrieved from https:// doi.org/10.1007/s11069-010-9660-0 doi: 10.1007/s11069-010-9660-0

Singh, J., Giri, R. K., \& Kant, S. (2007). Radiation fog viewed by INSAT-1 D and Kalpana Geo-Stationary satellite. Mausam, 58(2), 251.

Singh, J., \& Kant, S. (2006). Radiation fog over north India during winter from 1989-2004. Mausam, 57(2), 271.

Stull, R. B. (2012). An introduction to boundary layer meteorology (Vol. 13). Springer Science \& Business Media.

Taylor, G. I. (1917). The formation of fog and mist. Quarterly Journal of the Royal Meteorological Society, 43(183), 241-268. Retrieved from https://rmets .onlinelibrary.wiley.com/doi/abs/10.1002/qj.49704318302 doi: 10.1002/qj .49704318302

Turner, A. G., \& Annamalai, H. (2012, August). Climate change and the South Asian summer monsoon. Nature Climate Change, 2(8), 587-595. Retrieved from https://www.nature.com/articles/nclimate1495 doi: 10.1038/nclimate1495 
Willett, H. C. (1928). Fog and haze, their causes, distribution, and forecasting. Monthly Weather Review. doi: https://doi.org/10.1175/1520-0493(1928)56\% 3C435:FAHTCD\%3E2.0.CO;2

Wyngaard, J. C. (2010). Turbulence in the Atmosphere (First ed.). Cambridge University Press. doi: 10.1017/CBO9780511840524

Yadav, R. K., Kumar, K. R., \& Rajeevan, M. (2012). Characteristic features of winter precipitation and its variability over northwest India. Journal of Earth System Science, 121(3), 611-623. doi: https://doi.org/10.1007/s12040-012-0184-8 

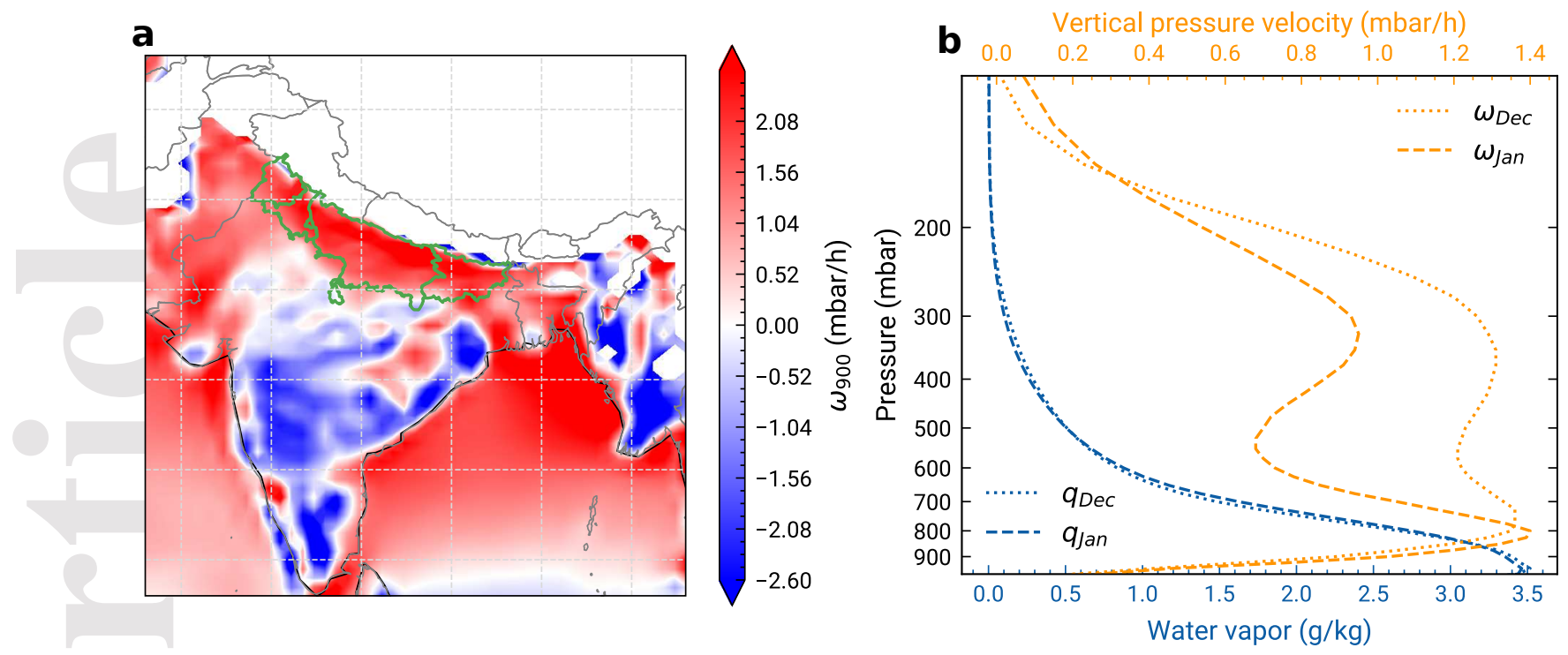

This article is protected by copyright. All rights reserved. 

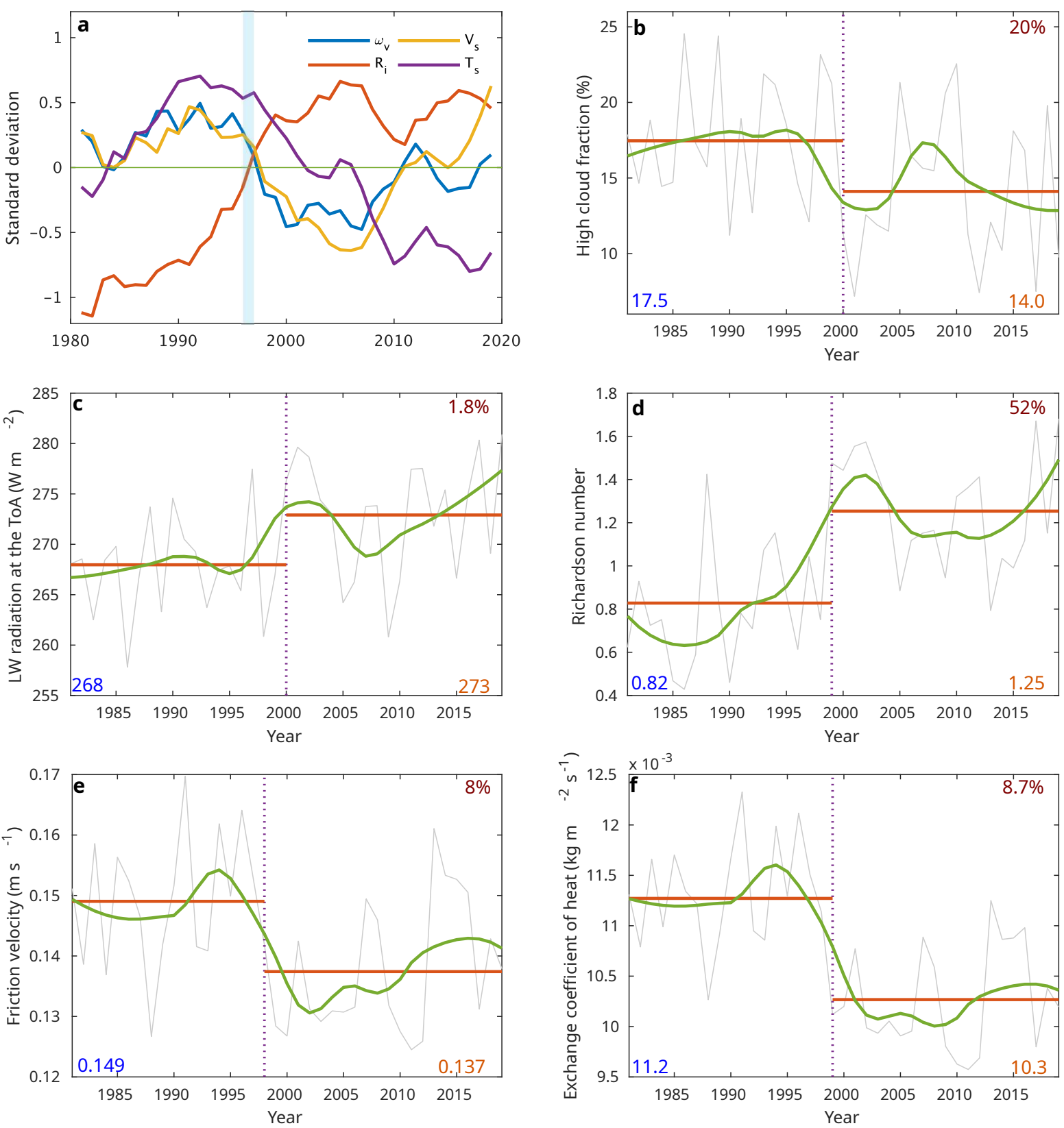

This article is protected by copyright. All rights reserved. 

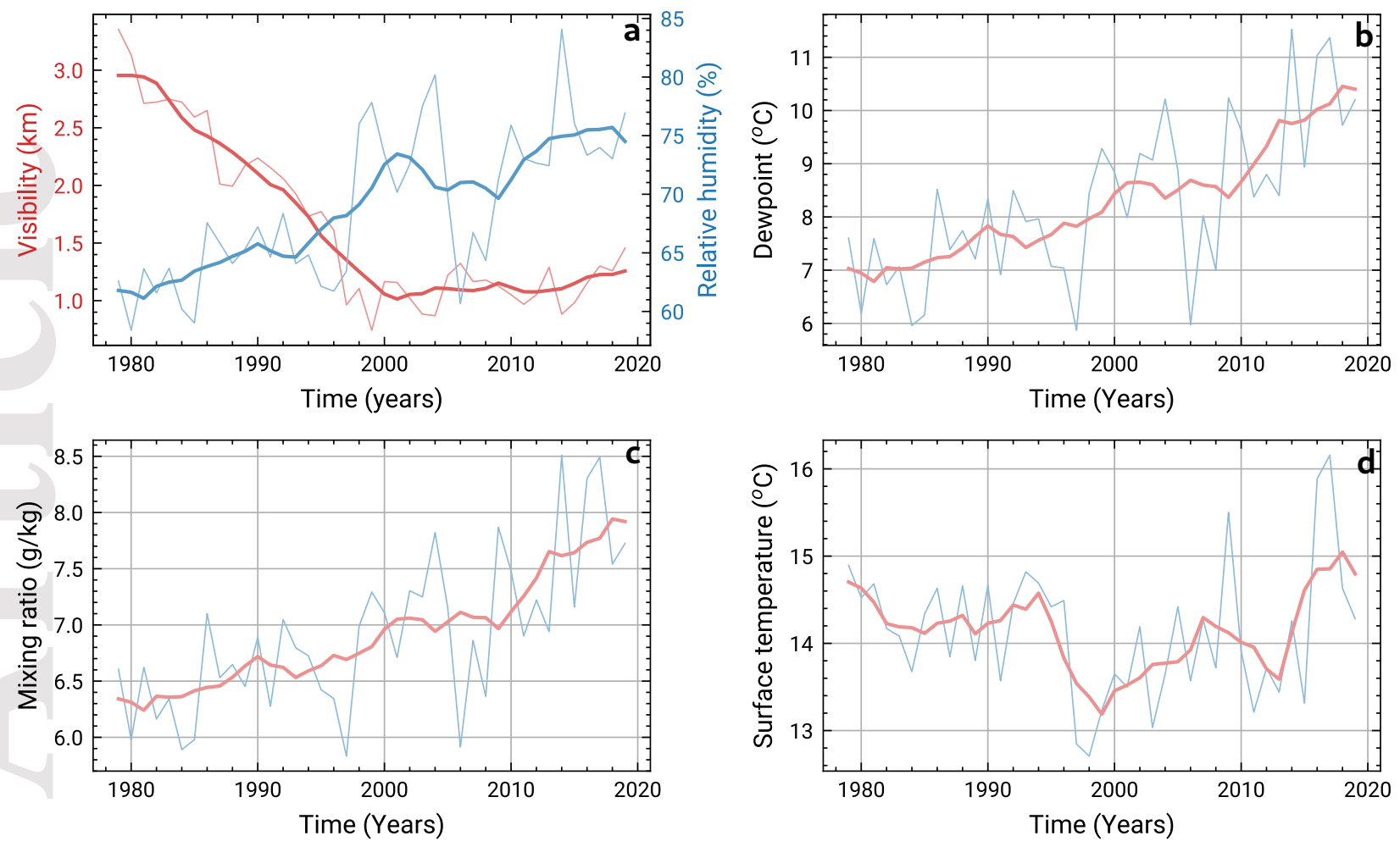

This article is protected by copyright. All rights reserved. 


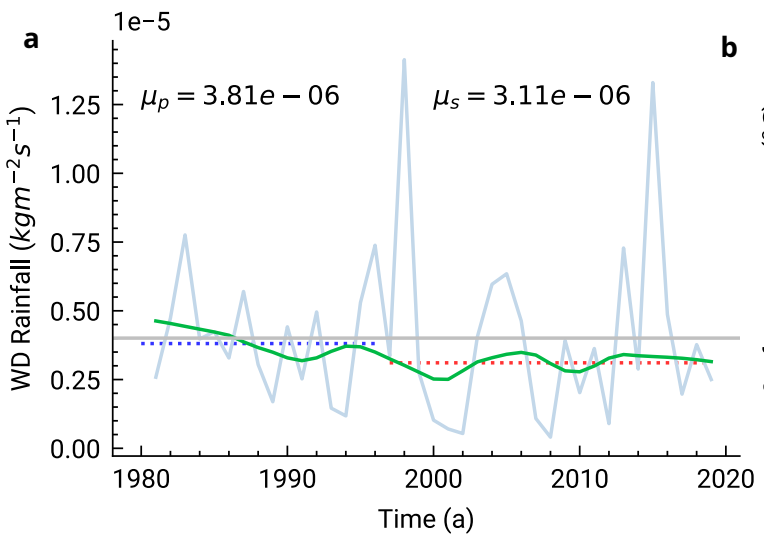

C

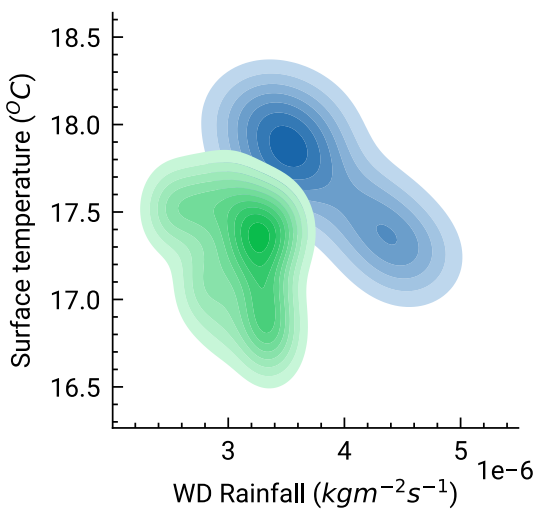

d $\quad 1 \mathrm{e} 6$

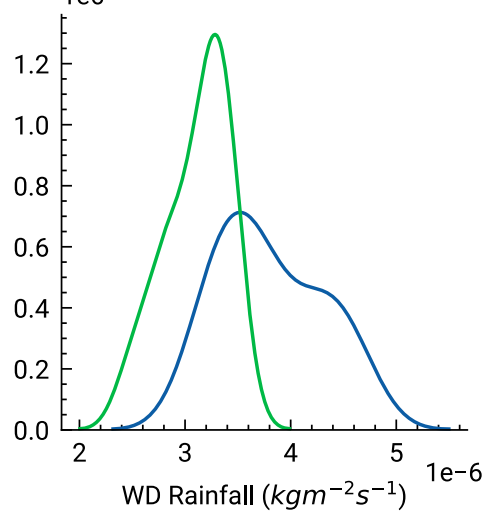

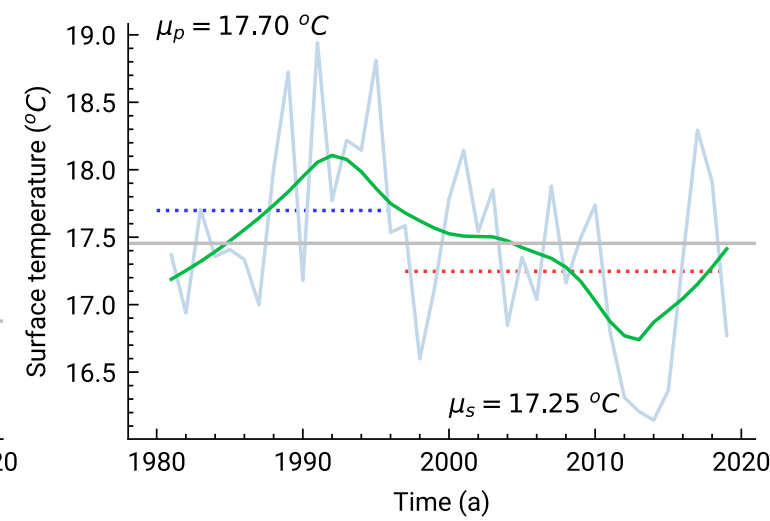

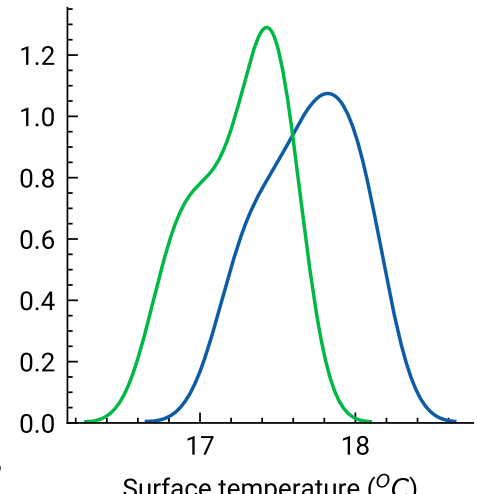

This article is protected by copyright. All rights reserved. 